\title{
DESEMPENHO AMBIENTAL EM INDÚSTRIAS DE BASE FLORESTAL - ESTUDO DE CASO NA REGIÃO CENTRO-SUL DO PARANÁ
}

\section{ENVIRONMENTAL PERFORMANCE IN FORESTRY INDUSTRY - A CASE STUDY IN SOUTH-CENTRAL REGION OF PARANA - BRAZIL}

\author{
Waldir Nagel Schirmer ${ }^{1}$; Mayara Ananda Gauer ${ }^{2}$; Éverton Hillig ${ }^{3}$; Daniel Bartiko ${ }^{4}$ \\ ${ }^{1}$ Universidade Estadual do Centro-Oeste - UNICENTRO - Irati - Brasil \\ wanasch@yahoo.com.br \\ ${ }^{2}$ Universidade Estadual do Centro-Oeste - UNICENTRO - Irati - Brasil \\ mayaragauer@yahoo.com.br \\ ${ }^{3}$ Universidade Estadual do Centro-Oeste - UNICENTRO - Irati - Brasil \\ ehillig@hotmail.com \\ ${ }^{4}$ Universidade Estadual do Centro-Oeste - UNICENTRO - Irati - Brasil \\ danielbartiko@hotmail.com
}

\begin{abstract}
Resumo
As indústrias de base florestal são responsáveis pela geração de grandes quantidades de resíduos, cujo volume e natureza variam em função das características do processo produtivo empregado. A transformação da madeira, que não é totalmente aproveitada, gera sobras como os retalhos, $o$ cepilho ou maravalha, a serragem e o pó. Apesar de o desperdício no setor madeireiro ser muito grande, raramente as empresas de base florestal exercem práticas de gestão ambiental. O principal objetivo deste trabalho foi avaliar o desempenho ambiental de indústrias de base florestal - que atuam no setor de fabricação de compensados, localizadas na região Centro-Sul do Paraná, propondo ainda alternativas customizadas de gestão ambiental para estas empresas. Para tanto, foram aplicados questionários nestas empresas, buscando realizar um diagnóstico da situação ambiental atual e identificar os passivos ambientais destas unidades produtivas. Constatou-se que todas as empresas possuem preocupação com as questões ambientais, embora empreendam poucas ações destinadas à melhoria do desempenho ambiental. Além disso, verificou-se que todas elas possuem passivos ambientais, especialmente grande geração de resíduos sólidos, líquidos e gasosos. Dentre as propostas de gestão ambiental citam-se a adoção de práticas de controle de geração de resíduos na fonte, o uso dos resíduos florestais como biomassa na produção de energia, a fabricação de briquetes e a substituição de produtos tóxicos. Concluiu-se que as práticas de gestão ambiental ainda são tênues nas empresas avaliadas e que não existe um controle adequado da geração de resíduos, sendo necessárias medidas de adequação ambiental de todo setor produtivo.
\end{abstract}

Palavras-chave: gestão ambiental; setor madeireiro; resíduos sólidos.

\section{Introdução}

As indústrias de base florestal são responsáveis pela geração de grandes quantidades de resíduos, cujo volume e natureza variam em função das características do processo produtivo 
empregado. A transformação da madeira, que não é totalmente aproveitada, gera sobras como os retalhos (compreendendo os resíduos maiores como aparas e cavacos), o cepilho ou maravalha (resíduo encontrado especialmente em indústrias de beneficiamento da madeira), a serragem (resíduo gerado pelo processo de usinagem com serras) e o pó de serra proveniente das operações de lixamento (DOBROVOLSKI, 1999, citado por LIMA e SILVA, 2005; NAHUZ, 2005; SILVA, 2009). Nas indústrias de compensados, ainda são gerados resíduos na forma de casca e de roloresto.

Além dos resíduos de origem florestal, fazem parte do produto acabado, metais (como aço, latão, alumínio, utilizados em puxadores, dobradiças, corrediças, etc.), vidros e cristais; produtos químicos (tintas, solventes, colas, vernizes, etc.); plásticos (fitas de borda, lâminas, puxadores, deslizadores, etc.) e tecidos e couros (naturais e sintéticos) (NAHUZ, 2005).

De acordo com a Associação Brasileira de Normas Técnicas (ABNT), os resíduos sólidos são definidos como:

\footnotetext{
Todo resíduo nos estados sólido e semi-sólido, que resultam de atividades de origem industrial, doméstica, hospitalar, comercial, agrícola, de serviços e de varrição. Ficam incluídos nesta definição os lodos provenientes de sistemas de tratamento de água, aqueles gerados em equipamentos e instalações de controle de poluição, bem como determinados líquidos cujas particularidades tornem inviável o seu lançamento na rede pública de esgotos ou corpos de água, ou exijam para isso soluções técnicas e economicamente inviáveis em face à melhor tecnologia disponível (ABNT NBR 10.004, 2004).
}

Esta mesma norma também classifica os resíduos sólidos em classe I (perigosos), classe IIA (não perigosos) e classe IIB (inertes). Essa classificação é feita com base na identificação do processo ou atividade que originou o resíduo, suas características físicas, químicas e biológicas e, também, por meio de comparações com listagens de resíduos já identificados e classificados (KOZAK et al., 2008).

Conforme Mady (2000), citado por Coronel et al (2008), o desperdício no setor madeireiro é grande, sendo que do volume total de uma tora, por exemplo, apenas 40 a $60 \%$ são aproveitados, o que gera uma quantidade significativa de sobras. Apesar disso, estas indústrias raramente dispõem de planos de gestão para seus resíduos já que, conforme dados obtidos por Nahuz (2005), menos de $5 \%$ das empresas de base florestal exercem alguma prática de conservação e de minimização de impactos ambientais negativos gerados por suas atividades.

No ramo moveleiro, por exemplo, de acordo com Uliana e Nolasco (2009), a não incorporação de uma política efetiva de gestão ambiental deve-se principalmente aos seguintes fatores, dentre outros: baixa capacidade de investimento (geralmente se tratam de empresas de pequeno e médio portes); emprego de baixa tecnologia no setor produtivo; clientes pouco exigentes com relação às questões ambientais; baixa capacitação operacional e até administrativa. Como 
adoção de prática ambiental, cabe ao setor moveleiro optar por dois tipos de gestão (ou a associação de ambos):

- Métodos diretos de tratamento (as chamadas tecnologias de "fim-de-tubo"), voltadas essencialmente ao tratamento/disposição dos resíduos ou, ainda;

- Métodos indiretos de tratamento, resultando diretamente numa redução (na fonte) das matérias primas empregadas na produção.

As chamadas tecnologias de fim de tubo compreendem um sistema de gestão cujo objetivo de tratamento dos resíduos não contempla o controle na fonte, já que atuam depois de sua geração (como o uso de ciclones e filtros-manga para controle de particulados, lavadores para o controle de gases e também particulados, etc.). Tem-se, dessa forma, custos elevados para o tratamento desses resíduos, já que grande parte da sua disposição dá-se por meio de equipamentos gerando, por exemplo, custos com aquisição e manutenção dos mesmos (além da mão-de-obra necessária à sua operação). Além disso, o processo de remediação desses resíduos muitas vezes acaba gerando outros resíduos que também precisam de algum tipo de tratamento secundário ou disposição, mesmo porque a geração do resíduo quase sempre é proporcional ao consumo da matéria-prima, o que acaba onerando todo o processo (FOCHI, 2007; KIPERSTOK et al., 2002; LORA, 2000).

Entretanto, o modelo de gestão baseado em métodos diretos vem perdendo adeptos, à medida que muitas empresas reconhecem os benefícios em se adotar medidas baseadas na prevenção da poluição. Mesmo procedimentos simples de gestão ambiental já são capazes de trazer às empresas não somente benefícios ambientais, mas também econômicos. Isso porque a gestão baseada na prevenção, a partir do momento que reduz o impacto na fonte, reduz também o desperdício de matérias primas e energia, convertidos comumente em resíduos sólidos, líquidos e gasosos, que sempre agregam custos aos processos produtivos gerando problemas ambientais que exigirão ainda mais custos para sua solução (LORA, 2000; KIPERSTOK et al., 2002).

Tendo em vista que as questões relacionadas ao desenvolvimento sustentável, preservação ambiental e cumprimento da legislação aplicável estão cada vez mais rigorosas, o controle da geração de resíduos, bem como seu reaproveitamento e reciclagem, podem se constituir também em fonte de lucro para as empresas. O correto gerenciamento dos resíduos pode trazer vantagens competitivas, já que evidencia o comprometimento ambiental da unidade produtiva (ZOLDAN, LEITE; PILATTI, 2006).

É evidente que a inserção da variável ambiental nas indústrias do segmento florestal pode trazer grandes ganhos. Ao se otimizar a linha de produção, reaproveitando e reciclando insumos (tipicamente madeireiros), menores quantidades de resíduos são geradas o que pode, inclusive, diminuir a pressão sobre as florestas nativas e exploração de sua madeira. A adoção de procedimentos de gestão do meio ambiente amplia as chances das indústrias madeireiras 
conquistarem novos mercados, bem como melhorarem seu desempenho ambiental (LIMA e SILVA, 2005; SABLOWSKI, 2003).

Quando se aborda o tema Gestão Ambiental, tanto no meio acadêmico como no empresarial, expressões como “tecnologias limpas" (ou mais limpas), "produção mais limpa”, etc. são cada vez mais comuns. Embora essas terminologias sejam diferentes, todas têm como ponto comum o foco na redução do desperdício ou mesmo a total prevenção da geração dos resíduos. A prevenção da poluição defende a exploração sustentável de fontes de matérias-primas e a redução no consumo de água e energia. Acrescenta ainda, que uma produção mais limpa deve se basear no princípio da precaução; avalia o ciclo de vida do produto-processo e seus principais pontos de impacto; limita o uso de aterros sanitários e outras formas de disposição mais onerosas ou ambientalmente incorretas; etc.

De acordo com Wittaczik (2003), o conceito de "tecnologia limpa" foi desenvolvido pelo Programa das Nações Unidas para o Meio Ambiente (PNUMA). Ainda, de acordo com Schenini (1999, citado por Wittaczik, 2003), as tecnologias limpas são entendidas como "todas as tecnologias, tanto a técnico-produtiva como a gerencial, que são utilizadas na produção de bens e serviços e que não afetam o meio ambiente". A implantação de um modelo de gestão que siga esses princípios pode abranger, por exemplo, a substituição de matérias-primas (por outras menos impactantes ao meio ambiente); a modificação do produto/processo, de modo a facilitar o reaproveitamento/reuso de sua matéria-prima constituinte; etc.

Sendo assim, este trabalho teve como principal objetivo avaliar o desempenho ambiental de indústrias de base florestal - que atuam no setor de fabricação de compensados -, localizadas na região Centro-Sul do Paraná, propondo ainda alternativas customizadas de gestão ambiental para estas empresas.

\section{Material e Métodos}

\subsection{Características gerais das empresas}

Os dados para esse estudo foram coletados em três empresas de compensados, de portes variados, localizadas na região Centro-Sul do Estado do Paraná. Todas as empresas avaliadas utilizam madeira proveniente de reflorestamento, principalmente de espécies do gênero Pinus. Das empresas, apenas uma não realiza a etapa de laminação, já que adquire as lâminas prontas de terceiros. Os fluxogramas dos processos produtivos empregados nas empresas são apresentados nas figuras 1 e 2 . 
Figura 1 - Fluxograma do processo produtivo das empresas 1 e 2

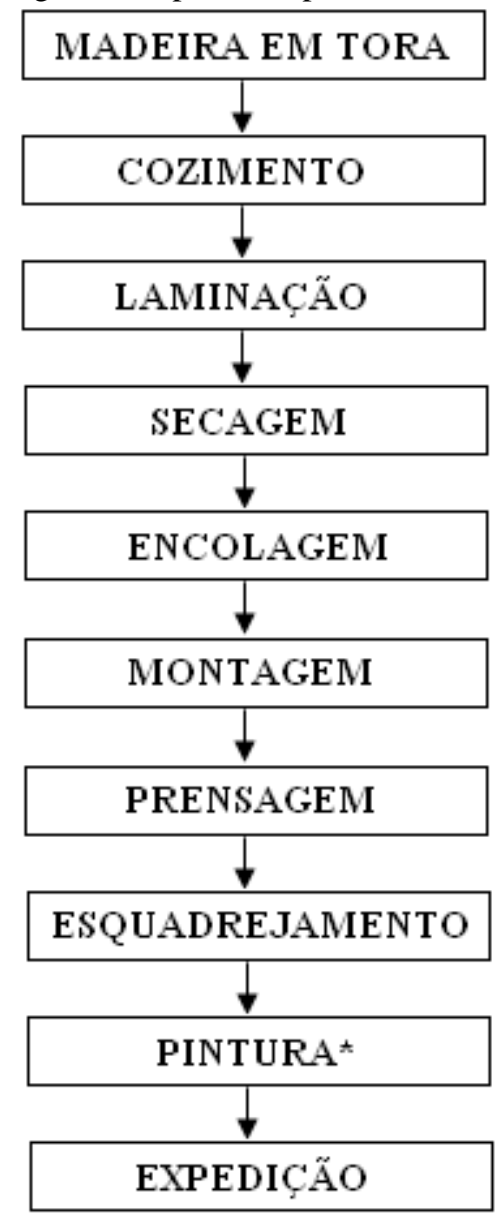

(*) Quando houver Fonte: Os autores

Figura 2 - Fluxograma do processo produtivo da empresa 3

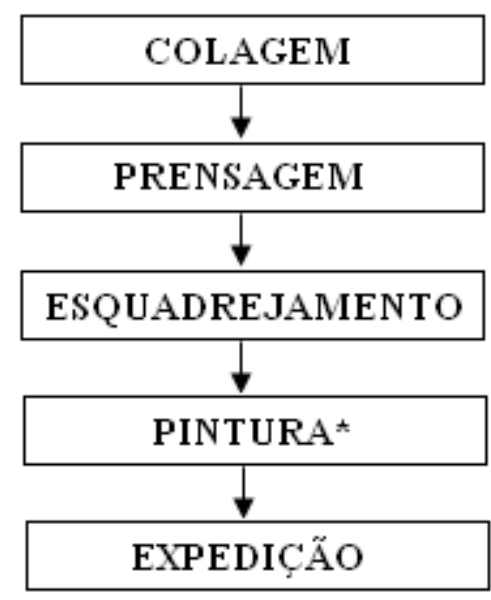

(*) Quando houver Fonte: Os autores

A empresa 1, de maior porte entre as envolvidas neste trabalho, conta atualmente com cerca de 100 funcionários para a realização de suas tarefas administrativas e produtivas. Já as empresas 2 e 3 possuem cerca de 25 funcionários cada uma. Nenhuma delas apresenta sistema de gestão ambiental efetivamente implantado até o momento. 


\subsection{Coleta de dados}

Para se avaliar o desempenho ambiental das empresas, foram aplicados questionários (com questões fechadas e baseadas naquelas utilizadas por Silva, 2001), constituídos de duas partes - uma relativa ao levantamento da situação ambiental das empresas (diagnóstico, abordando os aspectos ambientais associados às atividades da empresa num contexto atual) e a outra relacionada aos passivos ambientais.

Os questionários foram entregues aos diretores de cada empresa no primeiro semestre de 2009 e recolhidos no segundo semestre deste mesmo ano. Além da aplicação do questionário, foram feitas visitas técnicas às fábricas, como forma complementar de avaliação.

\section{Resultados e Discussão}

\subsection{Levantamento da situação ambiental das empresas}

De acordo com Barbieri (2004) apud Giacomet (2008), os Sistemas de Gestão Ambiental (SGA) podem ser definidos como um conjunto de atividades, tanto administrativas quanto operacionais, que visam identificar os problemas ambientais atuais de uma organização de modo a minimizá-los ou, até mesmo, eliminá-los no futuro.

Todas as três empresas pesquisadas nesse trabalho afirmaram ter preocupação com as questões ambientais e apenas a empresa 3 disse ainda não ter transformado essa preocupação em algo concreto. No entanto, somente a empresa 1 admitiu ter iniciado a implantação de um SGA (mas ainda não vigente), devido a pressões do órgão ambiental fiscalizador e da legislação aplicável.

Salienta-se que apesar de os fornecedores, clientes e os órgãos de fiscalização ambiental estarem, atualmente, exigindo que as empresas tenham uma conduta ambientalmente correta, tal fato não ocorre nas empresas 2 e 3, que afirmaram que tanto o órgão estadual fiscalizador quanto os consumidores não influenciam na tomada de decisões ambientais.

As empresas 1 e 3 afirmaram que os procedimentos de controle ambiental, bem como as atividades com grande capacidade de gerar impactos negativos ao meio ambiente são comunicados aos seus colaboradores, de modo que haja um maior comprometimento de todos os setores. Apesar disso, não se deve limitar a comunicação dos problemas e possíveis soluções ambientais somente aos funcionários de uma organização. Para a melhoria de todo o processo produtivo, são necessárias ações efetivas e que atinjam toda a comunidade onde a indústria está inserida, de modo que a conscientização ambiental não se restrinja apenas àqueles que estão dentro das empresas, mas atinja toda a sociedade (SALAMONI; GALLON; MACHADO, 2007). 
No que se refere ao controle dos resíduos gerados, apenas a empresa 1 afirmou exercer algum controle na geração dos mesmos, porém a mesma não possui registros relativos a estes resíduos facilmente disponíveis e atualizados. Além disso, esta é a única empresa deste levantamento que possui equipamento ou técnica especificamente utilizada para o controle da poluição. Assim, verifica-se que as práticas de gestão ambiental nestas unidades produtivas ainda são incipientes e pouco efetivas.

Quando questionadas sobre quais de seus aspectos ambientais eram mais importantes no quesito de causar impactos ambientais significativos, a empresa 3 afirmou que os aspectos "utilização de produtos tóxicos", "produção de dejetos sólidos", "emissão de efluentes líquidos" e “emissão de efluentes gasosos" não eram pertinentes às suas atividades. No entanto, foi constatado em visitas técnicas a esta empresa, a existência de resíduos líquidos e sólidos espalhados pelo chão da fábrica, provenientes das etapas de colagem e prensagem. Estes resíduos ficam armazenados no próprio local de geração, deixando o ambiente sujo e atraindo vetores, além de liberarem compostos tóxicos, oriundos do adesivo utilizado na colagem.

Já para as demais empresas (1 e 2), os aspectos "consumo de água", "consumo de energia", “emissão de efluentes líquidos" e "ruídos" eram aqueles com maior potencial de causar impactos negativos ao ambiente. Destaca-se que, apesar de todas as três empregarem adesivos à base de formaldeído no processo de colagem das lâminas, nenhuma considerou este aspecto como relevante no sentido de causar impactos.

Dentre as ações operacionais destinadas a reduzir ou prevenir os impactos sobre o meio ambiente, novamente a empresa 3 afirmou que nenhuma das ações propostas se aplicariam ao seu caso. Já a empresa 1 respondeu que poderia reduzir ou racionalizar o uso de matérias-primas, substituir o uso de produtos tóxicos e adotar medidas para reduzir danos sonoros e a geração de resíduos sólidos e líquidos. Como esta empresa já empreendeu medidas destinadas à redução do consumo de água (como a instalação de cisternas para captação de água da chuva e posterior utilização desta na caldeira) e à redução de efluentes gasosos (instalação de filtros na chaminé da caldeira e de um lavador de gases por micro-aspersão ${ }^{1}$ ), a mesma acrescentou que, no momento, é inviável estabelecer melhorias nestes aspectos. Em relação à empresa 2, a mesma afirmou que poderia reciclar ou reusar materiais e reduzir seu consumo de água. Destaca-se que tanto a empresa 1 quanto a empresa 2 mostraram-se dispostas a reduzir, também, seu consumo de energia elétrica.

Apenas a empresa 1 já empreendeu ações administrativas destinadas a reduzir ou prevenir impactos sobre o meio ambiente, por meio da escolha de fornecedores pelo desempenho ambiental

\footnotetext{
${ }^{1}$ Esse sistema permite que parte da fuligem que seria eliminada pela chaminé entre em contato com água e fique armazenada em um tanque, sendo então encaminhada para a Estação de Tratamento de Efluentes da fábrica.
} 
e incentivo aos fornecedores por mais ações ambientais. Para a mesma, os "problemas ambientais claramente visíveis", "locais contaminados" e "acidentes com impactos sobre o meio ambiente", foram fatores considerados muito importantes para a tomada de decisões ambientais. Porém, para todas elas, questões como "pressão competitiva", "pressão dos mercados capitais" e "acordos internacionais", pouco ou nada interferem na tomada destas decisões.

Quando questionadas sobre quais as principais dificuldades na aplicação de ações ambientais dentro da empresa, todas consideraram a falta de recursos financeiros e o alto custo como os principais obstáculos. Além disso, para as empresas 1 e 2, a falta de motivação da direção geral também se constitui num obstáculo importante para a realização de mais ações ambientais nas empresas. Entretanto, aspectos como "falta de informações sobre os instrumentos disponíveis" e “falta de solução técnica viável” não são considerados como empecilho à aplicação de tais ações para estas empresas ( 1 e 2). Tanto para a empresa 1 como para a 3, a fraca demanda por produtos ambientalmente corretos também se constitui em um entrave à aplicação de ações ambientais. Todas afirmaram ainda que o mercado para seus produtos retraiu sensivelmente nos últimos três anos.

A Figura 3 relaciona o benefício dos efeitos que poderiam ser obtidos pelas empresas com a adoção de práticas de gestão ambiental (de acordo com as respostas nos questionários).

Figura 3 - Avaliação dos efeitos da realização de ações ambientais por parte das empresas

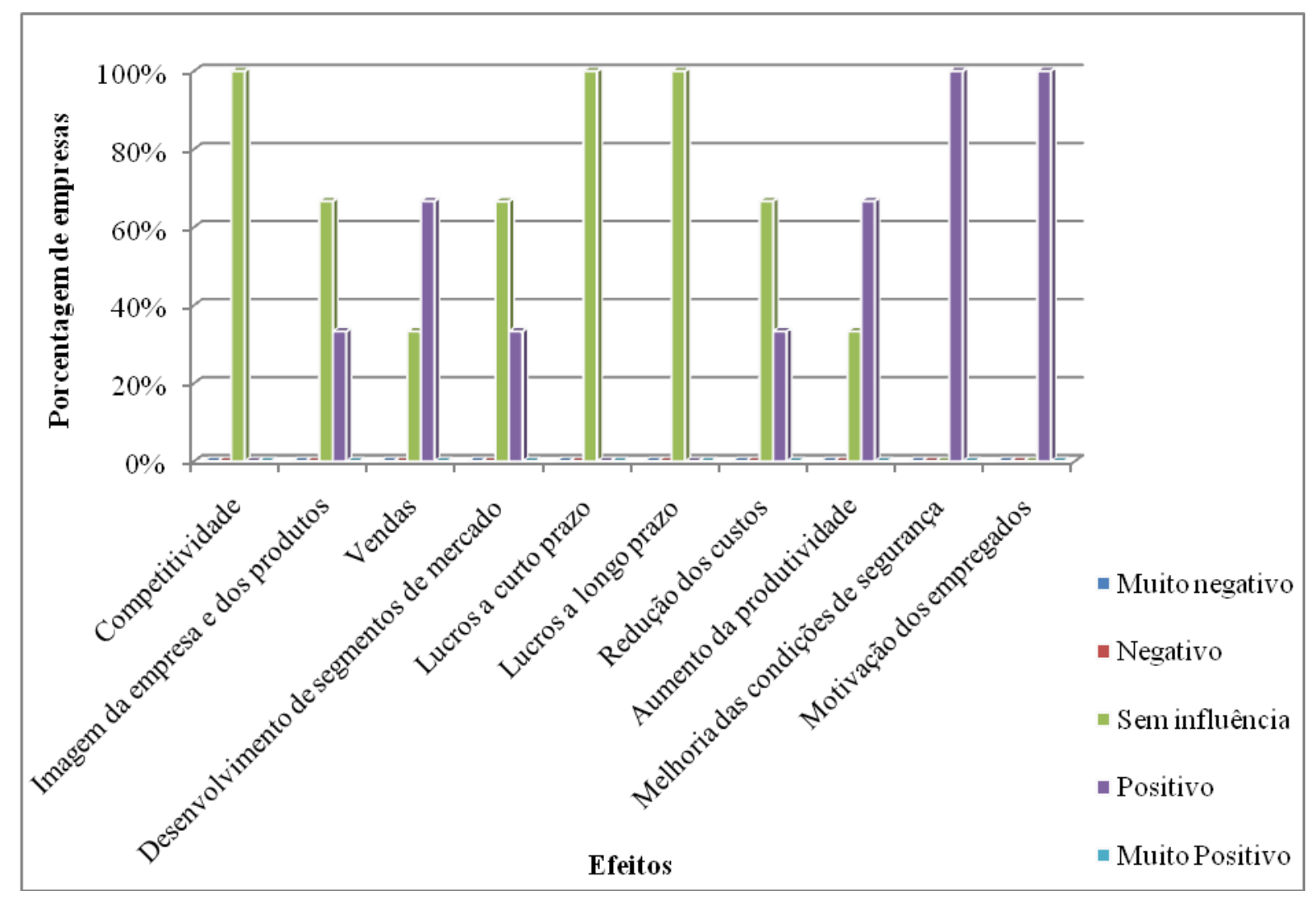

Fonte: Autoria Própria (2010) 
Pode-se observar que, pela percepção das empresas, a adoção de práticas ambientais não interferiria na sua competitividade e nos lucros a curto e longo prazos. Entretanto, as empresas consideram que tais práticas podem ser benéficas em relação à melhoria das condições de segurança e para a motivação dos empregados.

O fato de todas acreditarem que não irão auferir lucros ao incluírem a variável ambiental em seus processos produtivos pode ser explicado pelo desconhecimento, por grande parte das empresas, da importância de se avaliar seus custos ambientais. Quando as indústrias identificam estes custos, passam a compreender o quanto estão perdendo ou deixando de ganhar ao manterem processos e atividades que afetam o ambiente. Assim, é compromisso das empresas buscarem eliminar os impactos negativos de seu processo de produção, através do uso de novas tecnologias e práticas de gestão, ao mesmo tempo em que mantêm e obtêm novos ganhos econômicos (RIBEIRO, 1992 apud SALAMONI; GALLON; BEURENM, 2006).

\subsection{Passivos ambientais}

Em visitas técnicas às empresas avaliadas, contatou-se que as fábricas 1 e 2 apresentavam grande geração de resíduos líquidos (provenientes da etapa de cozimento das toras, encolagem das lâminas e prensagem), sólidos (gerados em diversas etapas do processo produtivo, como laminação e esquadrejamento e que se constituem principalmente em pedaços de lâminas e pó de madeira) e gasosos (vapores provenientes da colagem e emissões da chaminé da caldeira). Ambas utilizam as sobras da produção (restos de lâmina, cepilho e serragem) nas caldeiras, para a geração de vapor. Entretanto, em relação aos efluentes líquidos e gasosos, somente a empresa 1 possui um sistema de tratamento para os mesmos. Resumidamente, os efluentes líquidos (sanitário e industrial), são coletados em conjunto, misturados e enviados à Estação de Tratamento de Efluentes da fábrica, que conta com um tanque com aeração e um filtro prensa. $\mathrm{O}$ tratamento empregado consiste na separação da parte sólida do efluente, na qual é utilizado um agente floculante (etapa química) e na degradação da matéria orgânica por microrganismos (etapa biológica). Após passar pelo tanque de aeração, o efluente segue para o filtro prensa que retira o excesso de umidade e forma uma torta de sólidos. Tanto a parte líquida tratada, quanto a parte sólida gerada são armazenadas e posteriormente reutilizadas na caldeira da empresa. Em se tratando dos resíduos gasosos, sua forma de tratamento já foi comentada anteriormente.

Em relação à empresa 3, somente uma parcela dos resíduos sólidos é destinada à queima na caldeira, sendo o restante armazenado na própria fábrica. Não há, assim como na empresa 2, alguma forma de tratamento de efluentes líquidos e gasosos, refletindo a falta de comprometimento ambiental das indústrias deste segmento. 
De modo geral, todas as empresas admitiram possuir passivos ambientais e que estes são armazenados dentro da própria fabrica, sendo reaproveitados quando possível (Figura 4).

Figura 4 - Relação das empresas com os passivos ambientais de suas atividades

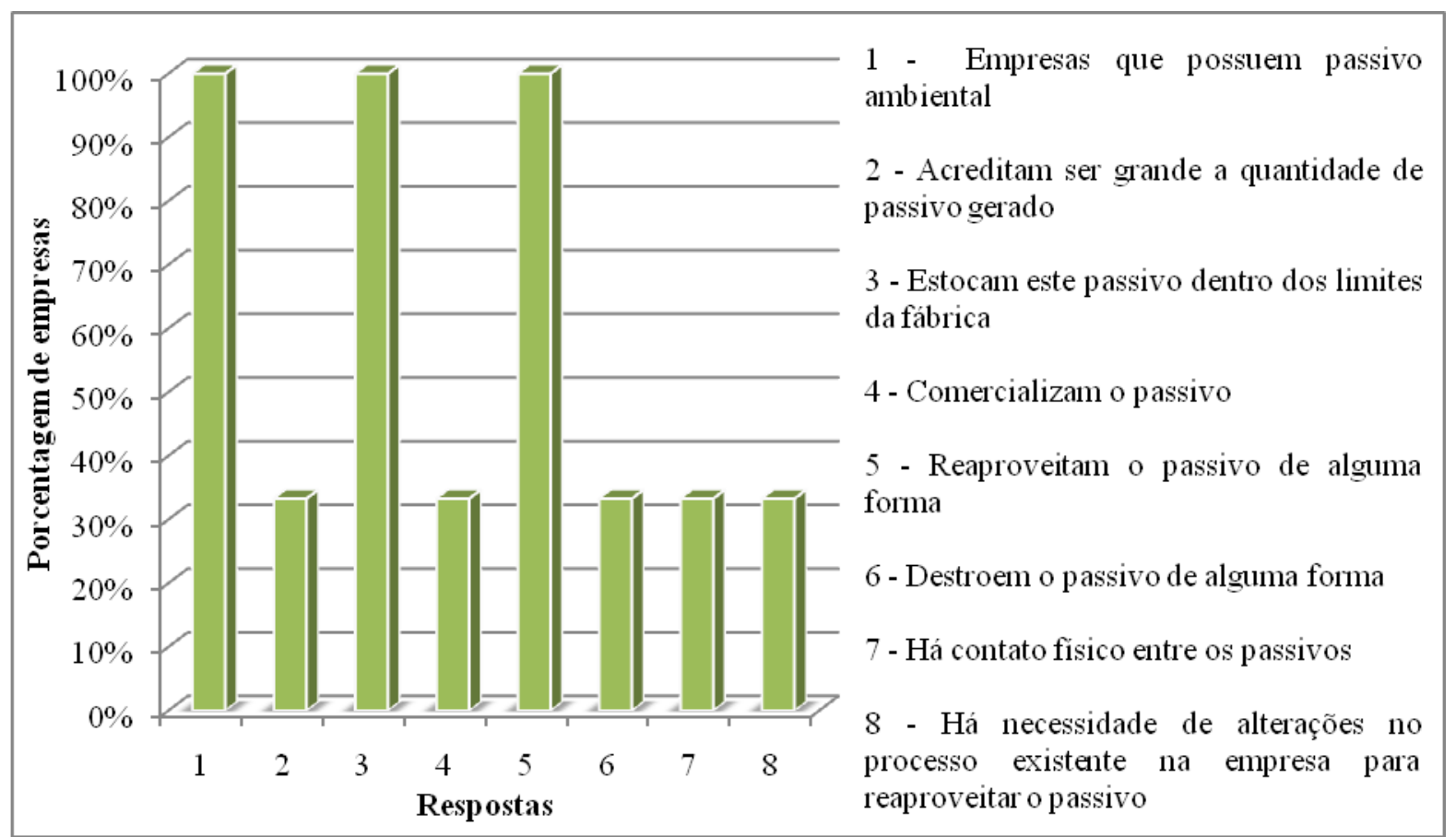

Fonte: Autoria Própria (2010)

\subsection{Propostas de gestão ambiental}

Com base nos questionários e nas visitas técnicas realizadas foi possível descobrir os pontos mais vulneráveis das empresas no que se refere às questões ambientais. Sendo assim, foram propostas algumas medidas básicas de gestão para a melhoria do desempenho ambiental dessas empresas.

Dada a grande quantidade de resíduos existentes nestas fábricas, a adoção de práticas de controle de geração de resíduos na fonte é um procedimento muito eficaz. Este controle pode ser conseguido pelo uso de materiais de maior durabilidade (que minimizam os desperdícios), pela substituição de matérias-primas e de tecnologias ou por meio de modificações nas práticas operacionais. Também um maior planejamento da produção pode evitar que se gere um volume expressivo de resíduos (ARGENTA, 2007)

O uso dos resíduos florestais como biomassa na produção de energia também vem sendo mais utilizado, devido ao seu poder calorífico representativo em relação a alguns combustíveis. Nesse caso, o consumo da biomassa economiza o uso de outros combustíveis comumente utilizados na indústria, como óleo BPF, gás natural, gás liquefeito de petróleo (GLP), etc. Outro modo bastante eficiente de utilizar resíduos madeireiros é sob a forma de briquete. Resumidamente, entende-se por briquetagem o processo de densificação energética da biomassa; na prática, 
corresponde à compactação de materiais ligno-celulósicos a elevadas pressões e temperaturas. Esse processo de compactação é simples, mas requer atenção a alguns parâmetros da matéria-prima: a umidade do material deve estar entre 8 e $15 \%$ e o tamanho máximo das partículas entre 5 e $10 \mathrm{~mm}$. $\mathrm{O}$ briquete pode ser alternativa energética viável. Apesar de seu menor valor energético por unidade de massa em relação a combustíveis tradicionais (como os derivados do petróleo), o uso do briquete pode ser estimulado pela possibilidade da obtenção de créditos de carbono. Comparativamente à lenha, por exemplo, o briquete apresenta mais vantagens, tanto por conta de sua menor umidade ( 8 a $10 \%$ frente aos $30 \%$ da lenha, em média) quanto poder calorífico (18.392 KJ/Kg contra 13.794 $\mathrm{KJ} / \mathrm{Kg}$ da lenha) (SILVA, 2007).

Observou-se também nessas empresas que a geração de material particulado (pó de madeira) decorrente de seus processos é bastante expressiva. Os sistemas de exaustão verificados nesses locais, quando existentes, não apresentavam eficiência de coleta necessária para recolher estes particulados, que acabam se depositando sobre as peças e maquinários, além de afetarem a saúde dos trabalhadores. Assim, sugere-se que sejam instalados sistemas de exaustão eficientes, projetados de acordo com as normas de ventilação, especialmente para cada situação (SCHIRMER; CORTEZ; KOZAK, 2008).

Outro problema presente nestas indústrias é a utilização de adesivos à base de formaldeído. Além da geração de efluentes perigosos que podem causar as colas de uréia-formaldeído e fenolformaldeído, as colas à base de uréia-formaldeído podem também causar a liberação de formol pelas chapas compensadas produzidas, o que não é recomendável. Dentre algumas alternativas disponíveis, pode-se sugerir que essas empresas façam alguns testes com adesivos novos que já foram usados em nível experimental. Dias (2005) considerou o adesivo poliuretano à base de mamona como promissor na fabricação de compensados e aglomerados. Argenta (2007) comenta que, atualmente, existem diversas alternativas disponíveis, como as colas à base de soja e milho e aquelas com dispersão em meio aquoso, menos tóxicas ao meio ambiente e à saúde do trabalhador.

\section{Conclusões}

Frente ao diagnóstico das empresas foi possível concluir que:

- As práticas de gestão ambiental ainda são tênues nas empresas avaliadas e não há um cumprimento, na íntegra, da legislação aplicável;

- Não existe um controle adequado da geração de resíduos, uma vez que as empresas desconhecem a porcentagem de resíduos gerados e reaproveitados;

- Apesar de todas as empresas afirmarem estar preocupadas com as questões ambientais, pouco tem sido feito neste aspecto. São necessárias medidas de adequação ambiental de todo setor produtivo, bem como relacionadas ao armazenamento e disposição final dos resíduos gerados; 
- Dentre todas as etapas do processo produtivo, a de cozimento de toras e colagem de lâminas merecem atenção especial, visto que geram resíduos perigosos (líquidos e atmosféricos) que, se não tratados e dispostos de forma correta, podem causar impactos ambientais diversos e inclusive afetar a saúde dos operadores (no caso do vapor de cola);

- Sugestões de gestão desses resíduos incluem controle na fonte da sua geração; readequação do produto/processo de modo a otimizar a utilização da matéria prima; substituição de matérias-primas por outras com menor impacto ambiental (quando possível); uso dos resíduos não reaproveitáveis no processo como fonte de energia (biomassa); projeto de ventilação voltado à captura de gases e particulados gerados no ambiente da fábrica; etc.

\begin{abstract}
The forest-based industries are responsible for generating large quantities of waste, whose volume and nature vary depending on the characteristics of the process employed. The wood manufacture is not widely used and begets leftovers like firewood, sawing and wood powder. Although the waste in the logger sector is very large, rarely forestbased companies engaged in environmental management practices. The main objective of this study was to evaluate the environmental performance of forest-based industries - that works in manufacturing plywood - located in south-central of Parana, Brazil, and proposes the alternative of customized environmental management for these companies. For both, questionnaires were applied in these companies, seeking out a diagnosis of current environmental situation and identify environmental liabilities of these production units. It was found that all companies have concerns about environmental issues, although few undertake actions to improve environmental performance. Moreover, it was found that they all have environmental liabilities, especially the great generation of solid, liquid and gaseous wastes. Among the proposals for environmental management can be cited the adoption of practices to control waste generation at source, the use of forest residues as biomass for energy, the production of briquettes and the replacement of toxic products. It was concluded that environmental management practices are still rare in evaluated companies and there isn't an adequate control of the generation of waste. So, measurements of environmental control are needed in all the productive sector.
\end{abstract}

Key-words: environmental management; wood industry; solid waste.

\title{
Referências
}

ARGENTA, D. O. F. Alternativas de melhoria no processo produtivo do setor moveleiro de santa maria/rs: impactos ambientais. 2007. 122 f. Dissertação (Mestrado em Engenharia de Produção) - Universidade Federal de Santa Maria, Santa Maria, 2007.

ASSOCIAÇÃO BRASILEIRA DE NORMAS TÉCNICAS (ABNT). NBR 10004. Resíduos sólidos: classificação. Rio de Janeiro, 2004. 71p.

BARBIERI, J. C. Gestão ambiental empresarial: conceitos, modelos e instrumentos. São Paulo: Saraiva. 2004.

CORONEL, D. A.; LAGO, A.; LENGLER, L.; SILVA, T. N. O aproveitamento dos resíduos do setor florestal de lages - Santa Catarina. Ciências Sociais em Perspectiva,v.12, , n.7, p. 75-92, 2008.

DIAS, F. M. Aplicação de resina poliuretana à base de mamona na fabricação de painéis de madeira compensada e aglomerada. 178f. Tese (Doutorado em Ciência e Engenharia de Materiais) - Universidade de São Paulo, São Carlos, 2005 .

DOBROVOLSKI, E. G. Problemas, destinação e volume dos resíduos da madeira na indústria de serrarias e laminadoras da região de Irati - PR. 1999. Monografia (Especialização em Engenharia de Segurança do Trabalho) Centro Federal de Educação Tecnológica do Paraná, Ponta Grossa, 1999.

FOCHI, P. L. O pólo moveleiro de Mirassol: práticas ambientais relacionadas ao ecodesign. 126f. Dissertação (Mestrado em Desenho Industrial) - Universidade Estadual Paulista Julio Mesquita Filho, Bauru (SP). 2007. 
GIACOMET, D. L. Avaliação do desempenho ambiental do processo produtivo de uma Indústria Madeireira. 2008. 104f. Dissertação (Mestrado em Engenharia da Produção) - Universidade Federal do Rio Grande do Sul, Porto Alegre, 2008.

KIPERSTOK, A.; COELHO, A.; TORRES, E. A.; MEIRA, C. C.; BRADLEY, S. P.; ROSEN, M. Tecnologias e gestão ambiental - prevenção da poluição. Brasília: Serviço Nacional de Aprendizagem Industrial (SENAI), 2002. 290 p.

KOZAK, P. A.; CORTEZ, A. M.; SCHIRMER, W. N.; CALDEIRA, M. V. W.; BALBINOT, R. Identificação, quantificação e classificação dos resíduos sólidos de uma fábrica de móveis. Revista Acadêmica, Ciência Agrárias e Ambientais, v.6, n.2, p. 203-212, 2008.

LIMA, E.G.; SILVA, D. A. Resíduos gerados em indústrias de móveis de madeira situadas no pólo moveleiro de Arapongas - PR. Revista Floresta, v. 35, n. 1, p. 105-116, 2005.

LORA, E. E. S. Prevenção e controle da poluição nos setores energético, industrial e de transporte. Agência Nacional de Energia Elétrica; Brasília (DF); 2000. 503p.

MADY, F.T.M. Conhecendo a madeira: informações sobre 90 espécies comerciais. Programa de Desenvolvimento Tecnológico. Manaus: SEBRAE, 2000. 212p.

NAHUZ, M. A. R. Resíduos da Indústria Moveleira: a cadeia produtiva de móveis no Brasil. São Paulo: IPT (Divisão de Produtos Florestais), 2005.

RIBEIRO, M. S. Contabilidade e meio ambiente. 1992. 141 f. Dissertação (Mestrado em Contabilidade) Universidade de São Paulo, São Paulo, 1992.

SABLOWSKI, A.R.M. Sistema de gestão ambiental no setor florestal. Revista da Madeira, n. 77, 2003. Disponível em <http://www.remade.com.br/br/revistadamadeira_capa.php?edicao=77> Acesso em: 16 mar. 2010.

SALAMONI, F. L.; GALlON, A. V.; MACHADO, D. D. N. Gestão ambiental e ações associadas aos custos ambientais em indústrias madeireiras de caçador, SC. ABCustos, v.2, n.1, p.21-41, 2007.

SALAMONI, F. L.; GALLON, A. V.; BEUREN, I. M. Gestão Ambiental e Ações Associadas aos Custos Ambientais em Indústrias Madeireiras Catarinenses. IN: SIMPÓSIO DE EXCELÊNCIA EM GESTÃO E TECNOLOGIA, 3, 2006, Rio de Janeiro. Anais... Resende, 2006.

SCHENINI, P. C. Avaliação dos padrões de competitividade à luz do desenvolvimento sustentável: o caso da Indústria Trombini papel e embalagens S/A em Santa Catarina - Brasil. Tese (Doutorado em Engenharia de Produção) Universidade Federal de Santa Catarina,Florianópolis. 1999.

SCHIRMER, W. N.; CORTEZ, A. M.; KOZAK, P. A. Ventilação industrial: uma ferramenta na gestão de resíduos atmosféricos em indústrias moveleiras - Estudo de caso. Revista de Ciências Ambientais, v. 02, n. 01, p. 15-28. 2008.

SILVA, A.B. Gestão ambiental na indústria: uma avaliação do comportamento dos setores químico e petroquímico com relação aos passivos ambientais e os problemas causados em torno da baía de Guanabara. 2001. 118f. Dissertação (Mestrado em Ciências na área de Saúde Pública) - Escola Nacional de Saúde Pública da Fundação Oswaldo Cruz, Rio de Janeiro, 2001.

SILVA, C. A. Estudo técnico-econômico da compactação de resíduos madeireiros para fins energéticos. $85 f$ f. Dissertação (Mestrado em Engenharia Mecânica) - Universidade Estadual de Campinas, Campinas. 2007.

SILVA, S. G. Resíduos sólidos: geração, tratamento e disposição - o caso das indústrias moveleiras de Arapongas. Disponível em: 〈http://www.amigosdanatureza.org.br/.../79.ResiduosSolidosTupa.doc〉. Acesso em: 05 nov. 2009.

ULIANA, L.R.; NOLASCO, A.M. diagnóstico da geração de resíduos na produção industrial de móveis como subsídio para a gestão empresarial. In: INTERNATIONAL WORKSHOP ADVANCES IN CLEANER PRODUCTION, 2 , 2009, São Paulo. Anais... São Paulo, 2009.

ZOLDAN, M.A.; LEITE, M.L.G.; PILATTI, L.A. Custos Ambientais em uma indústria madeireira - estudo de caso. IN: SIMPÓSIO DE ENGENHARIA DA PRODUÇÃO, 13, 2006, Bauru - SP, Brasil. 2006. 


\section{Agradecimentos}

Os autores agradecem à Fundação Araucária do Paraná e à Secretaria de Estado da Ciência, Tecnologia e Ensino Superior do Paraná pelo apoio financeiro. SET

\section{Dados dos Autores:}

Nome completo: Waldir Nagel Schirmer

Filiação institucional: Universidade Estadual do Centro-Oeste

Departamento: Engenharia Ambiental

Função ou cargo ocupado: Professor adjunto

Endereço completo para correspondência (bairro, cidade, estado, país e CEP): Bairro Riozinho, Irati (PR), Brasil, CEP 84.500-000

Telefones para contato: (42) 34213216

e-mail: wanasch@yahoo.com.br

Nome completo: Mayara Ananda Gauer

Filiação institucional: Universidade Estadual do Centro-Oeste

Departamento: Engenharia Ambiental

Função ou cargo ocupado: Professora colaboradora

Endereço completo para correspondência (bairro, cidade, estado, país e CEP): Bairro Riozinho, Irati (PR), Brasil, CEP 84.500-000

Telefones para contato: (42) 34213216

e-mail: mayaragauer@yahoo.com.br

Nome completo: Everton Hillig

Filiação institucional: Universidade Estadual do Centro-Oeste

Departamento: Engenharia Florestal

Função ou cargo ocupado: Professor adjunto

Endereço para correspondência (bairro, cidade, estado, país e CEP): Bairro Riozinho, Irati (PR), Brasil, CEP 84.500-000

Telefones para contato: (42) 34213088

e-mail: ehillig@hotmail.com

Nome completo: Daniel Bartiko

Filiação institucional: Universidade Estadual do Centro-Oeste

Departamento: Engenharia Ambiental 
Função ou cargo ocupado: Acadêmico da graduação e Engenharia Ambiental

Endereço para correspondência (bairro, cidade, estado, país e CEP): Bairro Riozinho, Irati (PR), Brasil, CEP 84.500-000

Telefones para contato: (42) 34213216

e-mail: danielbartiko@ hotmail.com

Recebido para publicação em: 26/04/2010

Aceito para publicação em: 10/08/2010 